\title{
Potencial de espécies comerciais analisado pelo índice de valor de importância em área de exploração de impacto reduzido
}

\author{
Potential of commercial species analyzed by the importance value index in a reduced impact \\ exploration area \\ Potencial de especies comerciales analizado por el índice de valor de importancia en un área de \\ exploración de impacto reducido
}

Recebido: 23/01/2021 | Revisado: 24/01/2021 | Aceito: 03/02/2021 | Publicado: 09/02/2021

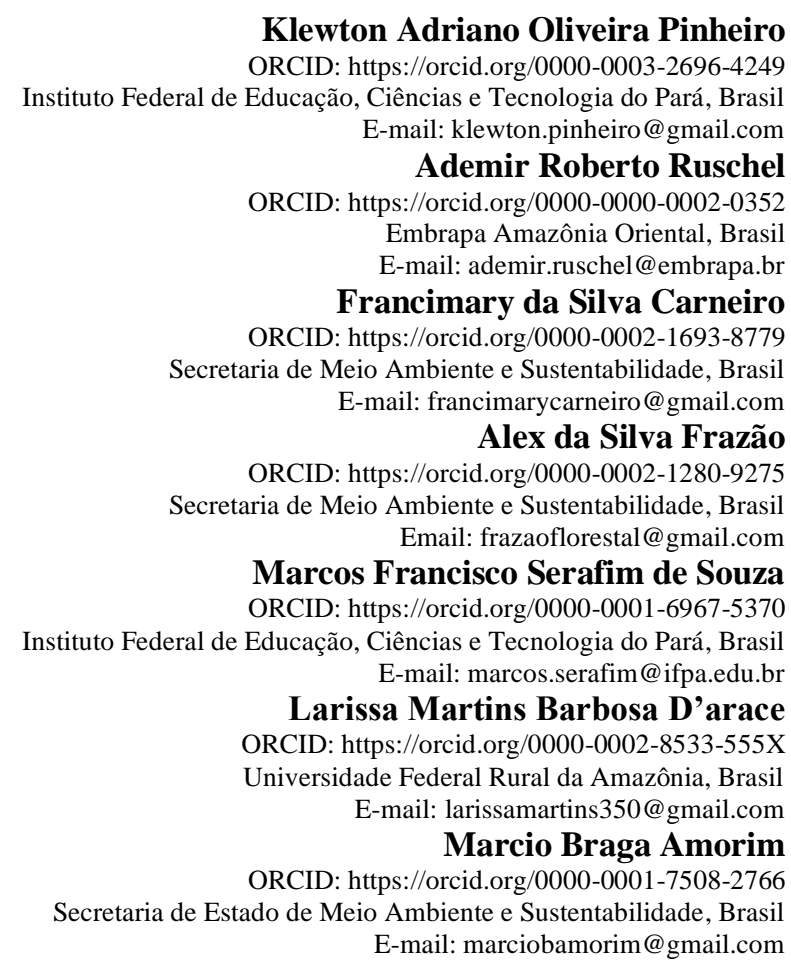

\begin{abstract}
Resumo
O objetivo deste trabalho foi avaliar o comportamento das espécies através do índice de valor de importância, verificamos as mudanças ocorridas na diversidade de árvores comerciais ao longo do tempo. A variedade de espécies foi determinada pelo Índice de Valor de Importância (IVI) e depois classificada em grupos de uso. Sapotaceae foi a família mais abundante em todo o estudo apresentando o maior volume e área basal. Pouteria spp., Goupia glabra e Manilkara huberi podem ser selecionadas para uma nova colheita devido a recuperação na taxa de crescimento. Atualmente, podem ser utilizadas para uma segunda colheita florestal 16 espécies comerciais somadas a mais 52 novas espécies. Devendo haver estudos de novas espécies para compor a exploração florestal levando em consideração a quantidade de indivíduos remanescentes, sua distribuição na área e a dominância dessa espécie em relação aos outros indivíduos.
\end{abstract}

Palavras-chave: Ecossistema florestal; Plano de manejo florestal; Espécies potenciais.

\begin{abstract}
The objective of this work was to evaluate the species' behavior through the importance value index, we verified the changes that occurred in the diversity of commercial trees over time. Species variety was determined by the Importance Value Index (IVI) and then classified into groups of use. Sapotaceae was the most abundant family in the entire study, with the largest volume and basal area. Pouteria spp., Goupia glabra and Manilkara huberi can be selected for a new harvest due to the recovery in growth rate. Currently, 16 commercial species can be used for a second forest harvest plus 52 new species. There must be studies of new species to compose the forest exploitation taking into account the number of remaining individuals, their distribution in the area and the dominance of this
\end{abstract}


species in relation to other individuals.

Keywords: Forest ecosystem; Forest management plan; Potential species.

\section{Resumen}

El objetivo de este trabajo fue evaluar el comportamiento de las especies a través del índice de valor de importancia, verificamos los cambios que ocurrieron en la diversidad de árboles comerciales a lo largo del tiempo. La variedad de especies se determinó mediante el Índice de valor de importancia (IVI) y luego se clasificó en grupos de uso. Sapotaceae fue la familia más abundante en todo el estudio, con mayor volumen y área basal. Pouteria spp., Goupia glabra y Manilkara huberi pueden seleccionarse para una nueva cosecha debido a la recuperación en la tasa de crecimiento. Actualmente, se pueden utilizar 16 especies comerciales para una segunda cosecha forestal más 52 especies nuevas. Se deben realizar estudios de nuevas especies para componer la explotación forestal teniendo en cuenta el número de individuos remanentes, su distribución en el area y la dominancia de esta especie en relación a otros individuos.

Palabra clave: Ecosistema forestal; Plan de manejo forestal; Especies potenciales.

\section{Introdução}

Vários estudos são voltados para o conhecimento e entendimento da estrutura da Floresta Amazônica, haja vista a complexidade dos diferentes fatores ambientais que influenciam na própria composição florística dos ecossistemas florestais (Silva et al., 2011). Para Carvalho (1997), um bom planejamento florestal é proporcionado pelo conhecimento da estrutura e da sua relação com a diversidade e produtividade da floresta. Araujo et al. (2010) citam que as florestas naturais apresentam muitas variáveis estruturadas por várias espécies, cada uma com diferente frequência, dominância e abundância de indivíduos, formando grupos que refletem as características da floresta que podem ser estudadas pela multivariada.

A estrutura horizontal de uma floresta resulta da combinação entre a somatória de densidade, frequência e dominância que tem como objetivo atribuir um valor de importância (IVI) para as espécies e permitir visualizar de forma ampla o desempenho das espécies na comunidade (Freitas \& Magalhães, 2012).

A seleção de espécies comerciais na exploração de impacto reduzido atrelada as novas ferramentas de monitoramento das florestas veem diminuindo os danos aos povoamentos. Porém, conhecer e utilizar o ciclo de corte compatível para a área e associar ao ritmo de crescimento das espécies manejadas fica para último plano em projetos de manejos florestais, equivocando-se nos valores sobre a taxa de extração anual do volume comercial (Putz et al., 2000).

A fragilidade dos ambientes florestais da Amazônia indica a necessidade de se conhecer a composição e distribuição das espécies vegetais nesses ecossistemas visando planificar de forma eficiente o manejo e a conservação da flora nativa regional. Os estudos florísticos e fitossociológicos são imprescindíveis, para conhecer a função das diferentes espécies de plantas na comunidade, bem como os habitats preferenciais de cada uma delas (Oliveira et al., 2008).

O IVI expressa a importância de uma determinada espécie dentre as árvores de uma comunidade florestal. Tem a finalidade de visualizar o desempenho das espécies na comunidade, suprir informações sobre estágios de desenvolvimento da comunidade e das populações, distribuição de recursos ambientais entre populações, possibilitando a utilização dos recursos vegetais de aplicação em estudos de vegetação e de fornecer a oportunidade de explorar e interpretar, de forma objetiva, os resultados dos seus estudos e, a partir deles, testar ou formular hipóteses de trabalho (ChaveS et al., 2013).

Dentro de todo esse contexto, buscamos verificar o comportamento das espécies comerciais através do índice de valor de importância e as mudanças ocorridas na composição florística e no crescimento em área basal de árvores comerciais ao longo de 27 anos, baseando-se na teoria de que o manejo de uma floresta primária pelo sistema seletivo pode acelerar os processos naturais e modificar a estrutura da floresta como a composição florística, riqueza, diversidade de espécies e estrutura diamétrica. 


\section{Material e Métodos}

O ecossistema florestal encontra-se na localidade Morro do Felipe no município de Vitória do Jari no estado do Amapá $\left(0^{\circ} 53^{\prime}\right.$ a $55^{\prime} \mathrm{S}$ e $52^{\circ} 10^{\prime}$ a $11^{\prime}$ W) a uma altitude de aproximadamente $150 \mathrm{~m}$. O clima nessa região é do tipo Ami pela classificação de Köppen. A precipitação média anual alcança $2.234 \mathrm{~mm}$ com um período chuvoso de dezembro a maio. Ocorre uma estação de seca de três meses que se inicia em junho e que se caracteriza por uma precipitação mensal inferior a $8 \%$ do volume anual de chuva. A temperatura média anual é de $25,80^{\circ} \mathrm{C}$. A vegetação é do tipo Floresta Ombrófila Densa. Apresenta o solo Latossolo Amarelo Distrófico com textura argilosa pesada (Azevedo et al., 2008).

Os parâmetros fitossociológicos da estrutura horizontal foram calculados segundo Souza (1973). A estrutura horizontal foi determinada utilizando o índice de valor de importância - IVI como variável de comparação entre as medições realizadas entre os anos de 1984 até 2011, sendo classificadas em grupos de exploração.

A estrutura da floresta foi calculada através da abundância, frequência e dominância das espécies na área estudada.

A abundância absoluta foi considerada como sendo o número de plantas de cada espécie na composição florística da área calculada pela relação do total de plantas de uma determinada espécie por unidade de área (ha).

A abundância relativa representa a participação de uma determinada espécie em relação ao total, expressa em porcentagem.

A frequência foi considerada com a distribuição de cada espécie, em termos percentuais, na área (Lamprecht, 1962). Frequência absoluta foi obtida pela percentagem de subparcelas em que ocorreu uma determinada espécie.

A frequência relativa foi considerada como a percentagem de subparcelas onde ocorreu uma determinada espécie em relação ao número total de subparcelas.

A dominância é a medida da projeção total do corpo da planta no solo e foi determinada através da área basal, ou seja, a soma das áreas transversais das plantas de uma determinada espécie.

A dominância relativa foi considerada como a percentagem de área basal de cada espécie em relação à área basal total.

O índice de valor de importância (IVI) foi determinado pela combinação, em uma única expressão, da abundância com a dominância e a frequência.

\section{Delineamento experimental}

O experimento foi iniciado em 1983 com a realização do inventário pré-exploratório considerando todas as árvores com Diâmetro à Altura do Peito $(\mathrm{DAP}) \geq 50 \mathrm{~cm}$. Em 1985 foi realizada a exploração florestal na área de floresta primária. Foram exploradas árvores com DAP $\geq 60 \mathrm{~cm}$ de 26 espécies de valor comercial na região, Azevedo et al. (2008).

Segundo Costa et al. (1998) a redução das áreas basais no desbaste sistêmico foi feita com base nas tabelas de distribuição de área basal dos anos de 1984 e 1994 e a escolha do diâmetro mínimo das árvores a serem eliminadas seguiu a somada área basal da maior para menor classe de diâmetro $(15-25 \mathrm{~cm})$ até obter um valor aproximado ao da área basal a ser eliminada. No desbaste seletivo de liberação, foram aneladas e envenenadas14 árvores por hectare de espécies não comerciais, cujas copas estavam competindo com espécies de interesse.

Os procedimentos para coleta e registro dos dados nas 36 parcelas permanentes de um hectare foram àqueles estabelecidos nas diretrizes propostas por Silva et al., (2005). Foram realizadas medições, antes da colheita e posteriores a colheita, nos anos de 1984, 1986, 1988, 1990, 1994, 1996, 2004 e 2011.

A identificação teve apoio do técnico botânico da Embrapa Amazônia Oriental. Foi coletado o material botânico das espécies menos comuns e dos grupos de espécies que suscitaram dúvidas, para ser identificado, através de comparação, no Herbário IAN da Embrapa Amazônia Oriental. 


\section{Coleta de dados}

O trecho da floresta foi selecionado através de parcelas permanentes. Selecionaram-se, exclusivamente, espécies arbóreas com Diâmetro à Altura do Peito (DAP) maior ou igual a 20cm.

\section{Análise de dados}

A estrutura diamétrica foi caracterizada por meio das distribuições do número de árvores, da área basal e do volume de fuste por hectare, por espécie e por classe de diâmetro em 36 ha do total de 108 ha da área experimental.

A avaliação da suficiência amostral foi feita supondo que as variáveis extraídas da população apresentaram uma distribuição que tende a uma normalidade. Neste caso, pode-se empregar a distribuição de probabilidades "t" associada ao erro padrão da média. Para verificar a suficiência amostral da composição florística, antes da aplicação dos tratamentos, os dados do número de espécies, em função da área, foram ajustados e analisados com a utilização do programa BioStat 3.0.

A estrutura diamétrica foi caracterizada por meio das distribuições do número de árvores, da área basal e do volume dos fustes por hectare, por espécie e por classe de diâmetro. Para executar essa análise as árvores foram agrupadas em classes de diâmetro (DAP) e separadas em três classes de tamanho: classe C-I (Classe- I) indivíduos registrados com $20 \mathrm{~cm} \leq \mathrm{DAP}<$ $30 \mathrm{~cm}$, classe C-II (Classe- II) registrados com $30 \mathrm{~cm} \leq$ DAP $<50 \mathrm{~cm}$ e a classe C-III (Classe -III) indivíduos registrados com $\mathrm{DAP} \geq 50 \mathrm{~cm}$.

Composição florística e estrutura diamétrica da floresta

Foi elaborada uma lista de espécies existentes na área com os nomes locais, nomes científicos, gêneros e famílias.

A estrutura diamétrica da floresta foi calculada através da abundância por classe diamétrica e foi determinado o estoque de volume entre florestas manejadas assim como para os diferentes tratamentos e entre as várias medições realizadas, através das equações de volumes de simples e dupla entrada:

Quantificar árvores entre $20 \leq \mathrm{DAP}<50 \mathrm{~cm}$ (Belém, 2010).

$$
\mathrm{V}=\mathrm{A} * \mathrm{H} * 0,7
$$

Quantificar árvores com DAP > $50 \mathrm{~cm}$ (Hiramatsu, 2008).

$$
V=-0,367921+0,0013446 * d 2
$$

Onde: A - área basal, $\mathrm{H}$ - altura e d - diâmetro

\section{Escolha de espécies comerciais em grupos}

Para conhecer a composição florística as espécies foram classificadas em três grupos: madeira branca, madeira mista e madeira nobre com alto valor comercial (adaptado de Reis et al., 2010). Na classificação foram utilizadas literaturas específicas e a lista de espécies exploradas pelo grupo Jari Celulose na Amazônia legal. Os nomes científicos foram tirados da base de dados de monitoramento de parcelas permanentes da área experimental inventário florestal apresentado pela Empresa.

Devido a grande diversidade biológica encontrada na área de estudo, as espécies florestais escolhidas para a segunda colheita tem que aparecer em todas as classes de tamanho, com ocorrência no banco de plântulas do sub-bosque com estoque para exploração; possuir taxa de crescimento acelerado; descritores de sanidade do fuste, podridão e cipó; ter fácil comercialização. Além dessas especificidades, as espécies foram separadas principalmente através de outras informações como: 
GI (madeira branca): Espécies pioneiras de rápido crescimento e ciclo de vida curto fazendo parte das fases iniciais de sucessão ecológica. Possui papel importante no processo de recuperação de áreas alteradas e restauração da floresta criando condições adequadas para o crescimento das espécies tolerantes.

GII (madeira mista): são espécies intermediárias da sucessão secundária. Essas espécies apresentam crescimento um pouco mais lento e ciclo de vida mais longo que as espécies do GI. Desenvolvem-se com pouca luz, tem densidade de madeira muito variável e com bom valor econômico para uso em carpintaria rústica e fabricação de móveis.

GIII (madeira nobre): São espécies típicas das etapas finais da sucessão florestal características da floresta madura e que geralmente apresentam crescimento lento, ciclo de vida longo, alta densidade de madeira e resistência ao sombreamento. Nesse grupo está a maioria das espécies conhecidas como "Madeiras de Lei”.

\section{Resultados e Discussão}

Considerando-se o teste de hipótese na comparação da floresta em termos de composição florística e volume total para o evento estudado, conclui-se que a hipótese nula (H0) é verdadeira, portanto, a somatória do volume total poderá ser igual e/ou maior que o volume comercial em um ciclo de corte.

Para o tamanho da amostra, obteve-se o Índice de Shannon-Weaver de 1.5420 nats/ind.O índice de Diversidade de Simpson de 0.9712.Índice de Equabilidade 0,9986. Coeficiente de Mistura de Jentsch foi de 1:17,39 representando 17,39 indivíduos por espécie para cada parcela comprovando a diversidade dessa floresta.

\section{Características estruturais e ecológicas das espécies comerciais}

Entre 1984 a 1990 foram registradas 39 famílias com uma única espécie e 13 espécimes identificadas somente em nível de família. Em 2004 foram registradas 58 famílias sendo 22 com uma única espécie, 176 gêneros e 14 espécimes identificados em nível de família.

As famílias Goupiaceae (131 ind.) e Cardiopteridaceae (143 ind.), apesar de apresentarem uma única espécie cada, possuem grandes abundâncias tornando-se promissoras para a próxima colheita e mesmo não aparecendo entre as 10 mais abundantes possuem grande importância ecológica e comercial. A espécie Cecropia Sciadophylla passou a ser a terceira mais abundante superando espécies como Manilkara huberi e Goupia glabra.

Desde 1980, a Goupia glabra é comercializada no mercado nacional e possui uma crescente abertura no mercado internacional. Conhecendo seu comportamento antes e após a exploração torna-se uma excelente espécie para o manejo. O estudo de autoecologia dessa espécie pode orientar nas decisões dos planos de manejo florestal e na aplicação dos sistemas silviculturais para promover aumento dessa população (HIRAI et al., 2007).

A população de árvores nesse período de estudo (1984-2011) apresentou um aumento de 80 espécies. Foram amostrados 6.304 indivíduos, distribuídos em 420 espécies, onde 15 indivíduos foram identificados em nível de família e 60 famílias botânicas, no último ano de medição.

Sapotaceae foi a mais abundante em todos os períodos de estudo, apresentando os maiores valores de volume e área basal seguida das famílias Fabaceae, Lecythidaceae, Apocynaceae e Lauraceae. Pinheiro et al. (2007) estudando a composição florística para a escolha de espécies para recuperação de áreas alteradas cita que a Sapotácea está entre as dez famílias botânicas com maior número de indivíduos, corroborando que esta família é uma das mais importantes economicamente na Amazônia brasileira.

Em 1985, ano de exploração, a família Fabaceae foi a mais explorada com 10 espécies, sendo representada neste estudo pelas espécies Vouacapoua americana, Hymenolobium sericeum, Hymenolobium excelsum, Hymenolobium petraeum, Dinizia excelsa, Dipteryx odorata, Vatairea spp., Hymenaea courbaril, Platymiscium spp. e Bowdichia nitida. A segunda 
família mais explorada foi Sapotaceae, representada por Pouteria oppositifolia, Manilkara huberi, Manilkara bidentata e Pouteria spp.

Geissospermum sericeum foi a espécie mais importante em termo de IVI, sendo registrada com os maiores valores de abundância, frequência e dominância, seguida por Goupia glabra, Manilkara huberi e Cecropia sciadophylla. Goupia glabra, apesar de aparecer em segundo lugar no ranque das mais importantes ecologicamente, apresentou maior área basal em relação as espécies Pouteria spp., Geissospermum sericeum e Manilkara huberi.

O IVI comporta-se como parâmetro indicativo do estado de recomposição da floresta ao estudo quantitativo da composição florística da estrutura, do funcionamento, da dinâmica, da distribuição e das relações ambientais da comunidade vegetal. Tem como finalidade atribuir valor para as espécies dentro da comunidade vegetal a que pertencem (Freitas \& Magalhães, 2012).

Cecropia sciadophylla é encontrada em formações secundárias e clareira no interior das florestas. Sua madeira é leve, fácil de trabalhar e recebe um bom acabamento, podendo ser empregada na caixotaria, forros, palitos de fósforo, pasta celulósica e balsa para transporte de madeira pesada nos rios amazônicos. Os frutos são consumidos por aves e morcegos e as folhas são o alimento do bicho-preguiça, veado, anta (Martins-Da-Silva, 2012).

Em 27 anos de monitoramento a Carapa guianensis, Licaria crassifolia e Platymiscium spp. apresentaram aumento no IVI, área basal e volume. O restante das espécies, após as intervenções por tratamento silvicultural e ou colheita ocorrida na área, decresceram. Qualea paraensis teve aumento de IVI e volume, devido ao aumento do número de árvores, e diminuição na área basal, diferente do que ocorreu com a Dinizia excelsa que teve aumento de volume e decréscimo no IVI.

Dentre as espécies exploradas, só configuraram entre as 20 mais importantes as Pouteria spp., Goupia glabra, Manilkara huberi, Dipteryx odorata, Pouteria oppositifolia e Manilkara bidentata. Entre essas espécies comerciais somente Pouteria spp. (305 ind.), Goupia glabra (127), Manilkara huberi (142) podem ser selecionadas para uma segunda colheita, devido a grande abundância de indivíduos e pela recuperação da taxa de crescimento que se aproximaram dos volumes e áreas basais iniciais.

Guatteria punctata, Mezilaurus itauba, Ocotea spp., Tovomita fructipendula, Naucleopsis caloneura, Alexa grandiflora,Byrsonima aerugo, Bellucia spp.,Casearia spp., Tachigali vulgaris, Osteophloeum platyspermumsão espécies de menor frequência na área, pois ocorreram apenas na última medição, portanto, os menores IVI. As espécies com baixa frequência e densidade podem ser classificadas como raras, utilizando o ponto de vista numérico, mas para a questão biológica pode não ser, visto que podem ocorrer em florestas próximas a área de estudo (Hack et al., 2005).

A Dipteryx odorata, Pouteria oppositifolia e Manilkara bidentata figuram entre as mais importantes espécies desse estudo. Apresentaram árvores para porta sementes, não recuperaram em volume e área basal e nem apresentaram indivíduos suficiente para futuras explorações.

Segundo Braz (2010), a exploração florestal de espécies comerciais, a partir da classe diamétrica de $85 \mathrm{~cm}$, sofre um decréscimo no crescimento após a exploração conduzindo a não sustentabilidade do sistema. Recomenda-se que as classes de 65 e 75 não podem ser extraídas totalmente, pois isto reduziria muito o incremento acumulado e que as extrações nessas classes devem ser cuidadosamente planejadas pensando no retorno futuro em incremento.

O que preconiza a Instrução Normativa N. 5, de 11 de dezembro de 2006, na seção 1, artigo 7, parágrafo primeiro, de que a redução do limite máximo de corte para $30 \mathrm{~m}^{3} \cdot \mathrm{ha}^{-1}$ de um grupo de espécies em uma exploração florestal pode levar a sustentabilidade da floresta dentro de 35 anos, sendo suficiente, porém necessitando de estudos por espécies para determinar seu manejo e corte.

Queiroz e Machado (2007) citam que para assegurar a manutenção das espécies exploradas em área de terra firme ou em várzea é preciso ter cuidado com as mudas e árvores jovens das espécies consideradas de valor comercial. Possuir 
capacidade de reposição e de produção de frutos e sementes, como é o caso da Mora paraensis, Carapa guianensis, Platymiscium filipes, Virola surinamensis e Symphonia globulifera, que representaram este comportamento neste estudo.

Segundo Braz et al., (2012), no plano de manejo florestal deve ser levado em consideração as taxas de cortes anuais e o ritmo de crescimento das espécies para garantir a sustentabilidade do sistema. Conhecendo as características fitossociológicas, ecológicas e a fenológicas das espécies pode tornar-se excelentes ferramentas para a recuperação da floresta.

Os parâmetros utilizados para calcular o IVI não eram o fator principal para a escolha de espécies para a exploração em 1980. A abundância de poucas espécies conhecidas comercialmente dominava o mercado de exploração florestal, por isso que espécies não conhecidas, mais com importância ecológica e grandes valores de IVI, não faziam parte da exploração. Temse como exemplo: Geissospermum sericeum, Eschweilera juruensis, Micropholis guyanensis, Virola michelii, Dendrobangia boliviana, Tachigali tinctoria, Corythophora rimosa e Protium sagotianum uma forma eficiente de fazê-las conhecidas no mercado é estudá-las em nível anatômico e das propriedades físicas e mecânicas.

As espécies mais abundantes foram: Geissospermum sericeum, Pouteria spp.,Manilkara huberi, Goupia glabra, Eschweilera juruensis, Dendrobangia boliviana, Micropholis guyanensis, Protium sagotianum, Virola michelii, Tachigali tinctoria, Protium opacum, Corythophora rimosa, Eschweilera coriacea, Iryanthera juruensis, Cecropia Sciadophylla e Ocotea douradensis.

\section{Grupos de espécie comerciais e suas classes de tamanho}

As espécies foram selecionadas em três grupos de exploração distintas, agrupamento pelas semelhanças, de acordo com os grupos ecológicos e uso da madeira conforme literatura existente. Para se conhecer o uso madeireiro da floresta as espécies foram classificadas em três categorias: MB: madeira branca, MM: madeira mista e MN: madeira nobre.

Das 435 espécies registradas no inventário florestal, em todo período de estudo, a Jari selecionou somente 26 espécies para a exploração em 1985 e dentro dos estados do Pará e Amapá existem hoje uma demanda de comercialização de aproximadamente 100 espécies. Dessas 100 espécies a Jari comercializa um grupo de 78 espécies no mercado local, principalmente no município de Almeirim/PA.

Neste estudo as espécies Licaria crassifolia, Qualea paraensis, Ruizterania albiflora e Caryocar villosum recuperaram seu volume inicial, e as espécies Vatairea spp., Nectandra micranthera e Platymiscium spp. chegaram próximas de recuperarem seus volumes e configuram no MB, podendo ser recomendada para uso em caixotaria, carvão e celulose, devido à baixa densidade da madeira.

Segundo Pinheiro e Schwartz (2009), Pouteria cuspidata, Pouteria venulosa, Goupia glabra, Vouacapoua americana, Dipteryx odorata, Platonia insignis, Hymenolobium ssp, Caryocar villosum, Bagassa guianensis e Psedopiptadenia suaveolens são espécies que apresentam alta aceitação no mercado interno e externo podendo ser utilizado nas serrarias, movelarias, industrias de construção civil e naval.

Souza et al., (2007) citam que espécies como Dipteryx odorata, Pouteria oppositifolia e Manilkara bidentata (classificados no $\mathrm{MM}$ ) apresentam uso diversificado na construção civil, movelaria, torneados e cabos de ferramentas, destacando a Dipteryx odorata na fabricação de dormentes, devido à elevada durabilidade. Consideradas de alto valor comercial encontram-se entre as mais exportadas pelas indústrias do Estado do Amapá, podendo entrar em extinção.

Mecanismos de proteção e estudos de autoecologias das espécies precisam ser levados em consideração para haver o aumento de suas populações, e neste caso, recomenda-se, através de outros estudos, um ciclo de corte maior, haja vista que as espécies Pouteria oppositifolia e Manilkara bidentata, neste estudo, chegaram próximas de recuperar seu volume inicial e a Dipteryx odorata caiu pela metade o seu volume. 
As espécies Handroanthus serratifolius, Hymenaea courbaril e Bowdichia nítida, classificadas no MN, foram indicadas para uso na marcenaria e carpintaria. O código Florestal sugere um ciclo de corte entre $30-40$ anos. Na área de estudo, essas espécies apresentam um alto déficit em volume e sugere-se o ciclo de corte de pelo menos o dobro do tempo proposto de acordo com as características de distribuição diamétrica de J-investido para as espécies.

Chipaia et al. (2015) usando a descrição anatômica da madeira de Vatairea sericea, Dinizia excelsa, Dipteryx odorata, Micropholis venulosa, Hymenaea courbaril, Manilkara huberi, Astronium lecointei e Caryocar brasiliense no município de Altamira-PA, indicaram para uso na construção civil, embarcações, construção naval, mobiliário e assoalhos.

Segundo Putz et al. (2000), grande parte das empresas florestais na Amazônia não associam as informações de incremento das espécies e a estrutura da floresta nas suas explorações florestais anuais. Não conhecem o potencial de recuperação da floresta e do quantitativo do estoque de volume extraído que poderá ser recuperado pela mesma em um ciclo de corte, portanto, não realiza o manejo florestal. Esse fato está ligado principalmente à oferta abundante de madeira de diversas espécies na Amazônia (Soares et al., 2014).

As espécies florestais da classe diamétrica C-I foram registradas entre $20 \mathrm{~cm} \leq \mathrm{DAP}<30 \mathrm{~cm}$, considerada de volume baixo, estando representadas por 2.970 árvores, com 567,4033 $\mathrm{m}^{3} \cdot \mathrm{ha}^{-1}$ volume total e área basal total de 139,8454 $\mathrm{m}^{2} . \mathrm{ha}^{-1}$, distribuídos em 58 famílias botânicas e 350 espécies, sendo 13 espécies identificadas em nível de família. Desse total, 14 indivíduos arbóreos não foram identificados formando um grupo de família denominada "Não Identificadas".

As espécies mais importantes na C-I em termo de abundância foram: Geissospermum sericeum (133 indivíduos), Pouteria spp. (123 ind.), Cecropia sciadophylla (89 ind.), Dendrobangia boliviana (71 ind.) e Eschweilera coriacea (61 ind.). Nesta classe foram registradas 107 espécies com um único indivíduo e 51 espécies com 2 indivíduos cada.

O aumento do número de árvores pequenas $(200 \mathrm{~cm} \leq \mathrm{DAP} \leq 30 \mathrm{~cm})$ pode ter sido favorecido pela retirada de área basal através do tratamento silvicultural. Segundo Carvalho et al. (2007) o crescimento de árvores juvenis anteriormente estabelecidos sugere que no local ocorreu alteração nos processos sucessionais internos e nos padrões estruturais.

Nos 36 hectares amostrados no inventário florestal foram encontrados 2.373 indivíduos arbóreos na classe C-II ( $30 \mathrm{~cm}$ $\leq$ DAP $<50 \mathrm{~cm}$ ), distribuídas em 279 espécies arbóreas e 49 famílias, com volume total de 551,8642 $\mathrm{m}^{3}$.ha-1 e área basal de $264,2462 \mathrm{~m}^{2} \cdot \mathrm{ha}^{-1}$. As cinco espécies sem identificações botânicas foram acrescentadas na listagem florística e utilizadas nas análises fitossociológicas da floresta.

A fitofisionomia dessa floresta caracterizou-se por um pequeno número de árvores altas e grossas com DAP $\geq 50 \mathrm{~cm}$ (C-III). Foram registrados 961 indivíduos amostrados em 35 famílias e 162 espécies botânicas com volume total de 275,9091 $\mathrm{m}^{3} \cdot \mathrm{ha}^{-1}$ e área basal de 339,9836 m².ha-1. Em 2011, somando as três categorias, obteve-se um volume total de $39.8625 \mathrm{~m}^{3} \cdot \mathrm{ha}^{-1}$, chegando a ultrapassar o volume comercial inicial de $39.1963 \mathrm{~m}^{3} \cdot \mathrm{ha}^{-1}$.

Segundo Hack et al., (2005) os estratos intermediário e superior concentram grande parte dos indivíduos encontrados demonstrando o avançado estágio de sucessão, além de que, a floresta ainda se recupera dos eventos ocorridos no passado (exploração, tratamento silvicultural e queda de árvores pela ventania).

Estudar o crescimento de árvores em seu habitat natural consiste em avaliar como elas são influenciadas pelos fatores climáticos e como ocorrem as mudanças de tamanho e na forma das plantas, para depois se planejar o manejo e a exploração florestal.

Deve-se estudar a autoecologia das espécies florestais para identificar como reagem aos fatores ambientais e como se dá a sua adaptação no ecossistema incluindo suas relações com outras espécies (Pires-O’brien; O’brien, 1995).

Machado et al. (2014) afirmam que as taxas de incremento no decorrer de um ano não estão relacionadas apenas com as condições climáticas, mas também com as reservas energéticas que a planta acumulou no último período de crescimento. 
Por sua vez Temps (2005), afirma que os modelos baseados em fatores climáticos podem influenciar no crescimento das árvores; tornando-se necessário o desenvolvimento de modelos que possam responder a essas mudanças. Machado (2014), pressupõe que o ritmo de crescimento decresce no inverno e possui forma acelerada na primavera e no verão, podendo apresentar similaridade com o comportamento do crescimento biológico ao longo de toda a vida do indivíduo.

Com a aplicação de tratamento silvicultural na floresta e o conhecimento da influência dos fatores climáticos no crescimento da floresta, concomitante a disponibilidade das espécies que comporão a taxa de corte, pode-se ter um manejo florestal sustentável sem desperdício de árvores na floresta (Oliveira et al., 2005).

\section{Considerações Finais}

A diversidade de espécies comerciais, ao longo de 27 anos de observação, refletiram na heterogeneidade florestal atual da área estudada com aumento de 80 espécies. É provável que na área de estudo as intervenções ocorridas proporcionaram um ambiente favorável ao desenvolvimento de determinadas espécies que aumentaram a riqueza e diversidade dessa área.

As espécies que conseguiram recuperar seu volume inicial apresentaram combinações importantes de densidade, frequência e dominância. Tiveram elevados valores de IVI e algumas espécies com baixa frequência apresentaram condição típica para árvores isoladas e dispersas na floresta.

O comportamento de algumas espécies, antes consideradas não comerciais, apresenta hoje, um potencial para comercialização através do índice de valor de importância - IVI, verificando as mudanças ocorridas na composição florística e no crescimento em área basal de árvores comerciais ao longo de todo o período de estudo.

Podem ser utilizadas na segunda colheita florestal 16 espécies comerciais (61\%) somadas a mais 52 novas espécies, além da colheita de cipó, resina, látex, cascas, frutos entre outros. A contribuição para o volume total deve ocorrer somando as árvores comerciais com espécies que passaram a ser comercial e que antes eram tidas como não comerciais na primeira exploração, assim, o somatório poderá ser igual e/ou maior que o volume inicial.

Existe uma grande quantidade de indivíduos jovens distribuídos nas três classes de tamanho que podem ser manejadas para futuras colheitas, desde que obedeçam a todos os princípios de sustentabilidades promovidos para a manutenção das florestas tropicais.

O estudo de autoecologia das espécies comerciais associado à estrutura remanescente e a manutenção das árvores por classe de tamanho, tem que ser levado em consideração nos planos de manejo florestais para garantir a sustentabilidade das espécies florestais. A exploração florestal tem que ocorrer baseada em estudos por espécies, e não somente por grupos de espécies, levando em consideração a quantidade de indivíduos remanescentes, sua distribuição na área, a dominância dessa espécie em relação aos outros indivíduos da mesma área e a importância que será destinada ao seu uso.

A grande quantidade de indivíduos arbóreos acima de $20 \mathrm{~cm}$ de DAP informa que está havendo renovação da vegetação e uma tendência de recuperação do volume inicial, porém, devemos manejar a floresta para alcançar a conservação e o desenvolvimento da natureza através da geração de produtos e serviços fornecidos pela floresta, caracterizando um novo processo.

\section{Referências}

Araujo, M. M., Chami, L., Longhi, S. J., Avila, A. L. De, \& Brena, D. A. (2010). Análise de agrupamento em remanescente de floresta ombrófila mista. Ciência Florestal, Santa Maria, 20(1), 1-18.

Azevedo, C. P. De, Silva, J. N. M., Souza, C. R. De, \& Sanquetta, C. R. (2012). Eficiência de tratamentos silviculturais por Anelamento na floresta do Jari, Amapá. Floresta, Curitiba, PR, 42(2), 315 - 324. 
Belém, Secretaria de Estado de Meio Ambiente, Francez, L. M. De B., Souza, D. V., Takehana, C. L. I., \& Barros, P. L. C. (2010). Manual para Análise de Inventário Florestal e Equação de Volume em Projetos de Manejo Florestal Sustentável - PMFS.66p.

Braz, E. M. (2010). Subsídios para o planejamento do manejo de florestas tropicais da Amazônia. 236 f. Tese (Doutorado) - Universidade Federal de Santa Maria, Santa Maria.

Braz, E. M., Schneider, P. R., Mattos, P. P. De, Thaines, F., Selle, G. L., Oliveira, M. F. De, \& Oliveira, L. C. (2012). Manejo da estrutura diamétrica remanescente de florestas tropicais. Ciência Florestal, Santa Maria, 22(4), 787-794.

Carvalho, F. A., Nascimento, M. T., \& Braga, J. M. A. (2007). Estrutura e composição florística do estrato arbóreo de um Remanescente de mata atlântica submontana no município de Rio Bonito, RJ, Brasil (mata rio vermelho). Revista Árvore, Viçosa-MG, 31(4), 717-730.

Carvalho, J. O. P. De. (1997) Dinâmica de florestas naturais e sua implicação para o manejo florestal. Curitiba, Documentos n34, EMBRAPA - CNPF, 41-55.

Chaves, A. D. C. G., Santos, R. M. De S., Santos, J. O. Dos, Fernandes, A. De A., \& Maracajá, P. B. (2013). A importância dos levantamentos florístico e fitossociológico para a conservação e preservação das florestas. Revista agropecuária científica no semiárido, 9(2), $42-48$.

Chipaia, F. C., Reis, A. R. S., Reis, L. P., Carvalho, J. C., \& Silva, E. F. R. (2015). Description anatomical macroscopic wood forest species of eight market in the municipality of Altamira-PA. Journal of Bioenergy and Food Science, 02 (1), 18-24. http://dx.doi.org/10.18067/jbfs.v2i1.14

Costa, D. H. M., Silva, S. M. A. Da, Silva, J. N. M., \& Ferreira, C. A. P. (1998). Desvitalização de arvores com tratamento silvicultural em floresta natural no município de vitória do Jari, Estado do Amapá. Pesquisa em Andamento. (184), 1-3.

Freitas, W. K. De, \& Magalhães, L. M. S. (2012). Métodos e Parâmetros para Estudo da Vegetação com Ênfase no Estrato Arbóreo. Floresta e Ambiente. 19(4):520-540.

Hack, C., Longhi, S. J., Boligon, A. A., Murari, A. B., \& Pauleski, D. T. (2005). Análise fitossociológica de um fragmento de floresta estacional decidual no município de Jaguari, RS. Ciência Rural, 35(5).

Hirai, E. H., Carvalho, J. O. P. De, \& Pinheiro, K. A. O. (2007). Comportamento populacional de cupiúba (Goupia glabra aubl.) em floresta de terra firme na fazenda rio capim, Paragominas (PA). Revista de Ciências Agrárias, Belém, (47), 89-101.

Hiramatsu, N. A. (2008). Equações de volume comercial para espécies nativas na região do Vale Do Jari, Amazônia Oriental. Dissertação 107p. Mestrado em Engenharia Florestal - Curso de Pós-Graduação em Engenharia Florestal, Setor de Ciências Agrárias, Universidade Federal do Paraná. Curitiba.

Machado, S. A., Zamin, N. T., Nascimento, R. G. M., \& Santos, A. A. P. dos. (2014). Efeito de Variáveis Climáticas no Crescimento Mensal de Pinus taeda e Araucaria angustifolia em Fase Juvenil. Floresta e Ambiente. abr./jun., 21(2):170-181.

Martins-Da-Silva, R. C. V., Gaglioti, A. L., Carvalho, L. T. De, Gomes, J. I., \& Margalho, L. (2012). Conhecendo Espécies de Plantas da Amazônia: Imbaubão (Cecropia sciadophylla Mart. - Urticaceae). Comunicado Técnico 234, Embrapa Amazônia Oriental. Belém, PA, Agosto, 4. https://ainfo.cnptia.embrapa.br/digital/bitstream/item/77509/1/Oriental-ComTec234.pdf

Melo, L. E. De L., Silva, C De. J., Urbinati, C. V., Santos, I. S., \& Soares, W. F. (2013). Variação Anatômica no Lenho de Astronium lecointei Ducke. Floresta e Ambiente, 20(1), 135-142.

Pereira, D. \& Guimarães, J. Verissimo, A. (2010). Boletim de preços de madeira na Amazônia: Imazon, 14 . http://imazon.org.br/PDFimazon/Portugues/precosdamadeira/Precos_05_SITE.pdf>.

Pinheiro, K. A. O., Carvalho, J. O. P. De, Quanz, Beatriz, Francez, L. M. De B., \& Schwartz, G. (2007). Fitossociologia de uma área de preservação permanente no leste da Amazônia: indicação de espécies para recuperação de áreas alteradas. FLORESTA, $37(2), 175$ - 187.

Pinheiro, K. A. O, \& Schwartz, G. (2009). Aspectos socioeconômicos da comercialização de produtos agrícolas e florestais em sete comunidades rurais no alto Moju, Estado do Pará. Amazônia: CI \& Desenv. Belém, 5(9), 41 -51.

Pires-O’brien, M. J., \& O’brien, C. M. 1995. Ecologia e Modelamento de Florestas Tropicais. FCAP, Serviço de Documentação e Informação. 400 p.

Putz, F. E., Dykstra, D. P., \& Heinrich, R. (2000.). Why poor logging practices persist in the tropics. Conservation Biology, Malden, $14(4)$, 951-956.

Queiroz, A. L. De, \& Machado, S. do A. (2007). Potencial de utilização madeireira de espécies florestais de várzea no município de Mazagão no estado do Amapá. Floresta, Curitiba, PR, 37(2), 293 - 302.

SEFA. Boletim informativo de preço de madeira. Secretaria Estadual de Fazenda do Pará, Belém, PA, p. 1 - 22, 2013. http://www.sefa.pa.gov.br/arquivos/icms/boletim_precos/2013/boletim_de_precos_minimos.pdf.

SEMAS. Extração e Comércio de Toras de Madeira Nativa por Município. Secretaria de Estado de Meio Ambiente e Sustentabilidade do Pará. Belém, PA, p. 1- 123. http://monitoramento.sema.pa.gov.br/sisflora/index.php/relatorios.Acesso: 27 jul. 2015.

Silva, K. E., Martins, S. V., Ribeiro, C. A. S, Santos, N. T, Azevedo, C. P., Matos, F. D. A. \& Amaral, I. L. (2011) Floristic composition and similarity of 15 hectares in Central Amazon, Brazil. Revista de Biologia Tropical, 59: 1927-1938.

Soares, W. F., Melo, L. E De. L., \& Lisboa, P. L. B. Anatomia do Lenho de Cinco Espécies Comercializadas como 'sucupira'. Floresta e Ambiente, 21(1), $114-125,2014$

Sousa, M. A. R. De, Moutinho, V. H. P., \& Silva, S. S. da. Levantamento das espécies comercializadas vernacularmente como cumaru no Estado do Pará. Revista Brasileira de Biociências, Porto Alegre, 5(1), 81-83. 
Research, Society and Development, v. 10, n. 2, e16610212292, 2021

(CC BY 4.0) | ISSN 2525-3409 | DOI: http://dx.doi.org/10.33448/rsd-v10i2.12292

Souza, D. R. De, Souza, A. L. De, Leite, H. G., \& Yared, J. A. G. Análise estrutural em floresta ombrófila densa de terra firme não explorada, Amazônia Oriental. Revista Árvore, 30, 75-87. 2006.

Souza, P. F. Terminologia Florestal - glossário de termos e expressões florestais. Rio de Janeiro: Fundação IBGE, 1973. 304 p.

Temps, M. Adição da precipitação pluviométrica na modelagem do crescimento e da produção florestal em povoamentos não desbastados de Pinus taeda L. [dissertação]. Curitiba: Universidade Federal do Paraná, 2005.

Ter Steege, H., Sabatier, D., Castellanos, H., Andel, T.V., Duivenvoorden, J., Oliveira, A. A., Renske, E., Lilwah, R., Maas, P., \& Mori S. A regional perspective: Analysis of Amazonian floristic composition and diversity that includes a Guyana Shield. In: H. TERSTEEGE (ed.). Plant Diversity in Guyana: Whit recommendations for a National Protected Areas Strategy. The Tropenbos Foundation, Wageningen. 19-32. 2000.

Valente, B. M Dos. R. T., Evangelista, W. V., Silva, J De. C., \& Lucia, R. M. D. Variabilidade radial e longitudinal das propriedades físicas e anatômicas da madeira de angico vermelho. Scientia Forestalis, 41(100), 485-496, 2013. 